\title{
Análise de trilha em genótipos de trigo submetidos ao estresse por encharcamento
}

\section{Pathway analyses in wheat genotypes under waterlogging stress}

\author{
Sydney Antonio Frehner Kavalco ${ }^{1 *}$; Ricardo Figueiredo ${ }^{2}$; Eder Licieri Groli²; \\ Cristiano Mathias Zimmer²; Diego Baretta ${ }^{3}$; Elisane Weber Tessmann ${ }^{3}$; \\ Ariano Martins de Magalhães Júnior ${ }^{4}$; Antonio Costa de Oliveira ${ }^{5}$
}

\section{Resumo}

A seleção indireta pode ser considerada uma estratégia interessante para o melhoramento de plantas, especialmente quando um caráter de fácil mensuração ou de maior herdabilidade estiver altamente correlacionado com um caráter de interesse, que apresente menor herdabilidade em populações segregantes. Os objetivos deste trabalho consistiram em obter estimativas de coeficientes de correlação fenotípica, genotípica e ambientais e avaliar os desdobramentos das correlações genotípicas em efeitos diretos e indiretos de variáveis agronômicas sobre o rendimento de grãos por meio da análise de dois ambientes de cultivo em quinze populações segregantes de trigo. Os caracteres agronômicos rendimento de grãos por planta (RG), número de grãos por espiga (NGE), peso dos grãos por espiga (PGE), massa de mil grãos (MMG), número de afilhos férteis (NAF), dias da emergência ao florescimento (DEF), dias do florescimento à maturação (DFM), ciclo total de desenvolvimento (CICLO), e acamamento (ACAM), foram avaliados em quinze populações segregantes $\mathrm{F}_{4}$ de trigo sob dois sistemas de cultivo (com e sem encharcamento). Em todas as populações avaliadas, por meio das correlações simples, a seleção de plantas mais produtivas pode ser realizada pela seleção indireta sobre NGE, PGE e NAF. Mediante a análise de trilha foi possível identificar o efeito indireto do caráter NGE sobre RG. Assim como o efeito do PGE, do NAF, do DEF e de CICLO como causadores da formação da correlação entre outros caracteres (NGE x RG, MMG x RG, de DFM x RG, de CICLO x RG e de ACAM x RG), enfatizando que o NGE, o PGE, o NAF, o DEF e que o CICLO são os principais caracteres a serem considerados para aumentar a produtividade de grãos em trigo.

Palavras-chave: Triticum aestivum L., seleção indireta, melhoramento de plantas, correlação entre caracteres

\footnotetext{
Abstract

Indirect selection can be considered an interesting strategy for plant breeding, especially when an easily measurable/high heritability trait is highly correlated with a target trait which has a lower heritability in segregating populations. The objective of this study was to obtain estimates of phenotypic, genotypic

${ }^{1}$ Discente do Curso de Doutorado e M.e em Biotecnologia- CDTEC, Universidade Federal de Pelotas, UFPel, Pelotas, RS. Bolsista da CAPES. E-mail: skavalco@gmail.com

${ }^{2}$ Discentes do Curso Graduação em Agronomia, UFPel, Pelotas, RS. E-mail: ricardorgf91@hotmail.com; elicierigroli@gmail. com; cmz.zimmer@gmail.com

${ }^{3}$ Discentes do Curso de Mestrado em Agronomia, Área de Concentração Fitomelhoramento, UFPel, Pelotas RS. E-mail: barettadiego@gmail.com; elisanetes@hotmail.com

${ }^{4}$ Pesquisador da Embrapa Clima Temperado, Estação Experimental Terras Baixas. Empresa Brasileira de Pesquisa Agropecuária EMBRAPA, Pelotas, RS. E-mail: ariano.martins@cpact.embrapa.br

${ }_{5}$ Prof. Associado do Dept ${ }^{\circ}$ de Fitotecnia, Faculdade de Agronomia Eliseu Maciel, UFPel. Pelotas, RS. E-mail:acostol@cgfufpel. org

* Autor para correspondência
} 
and environmental correlations and to evaluate the partition of genotypic correlations in direct and indirect effects of agronomic variables on the GY variable, through the analysis of two cultivated environments in fifteen wheat segregating populations. The agronomic traits grain yield per plant (GY), number of grains per ear (NGE), grain weight per ear (GWE), thousand grain weight (TGW), number of fertile tillers (NFT), days from emergence to flowering (DEF), days from flowering to maturity (DFM), total development cycle (CYC), and percentage of lodging (LODG), were evaluated in $\mathrm{F}_{4}$ populations under two cropping systems (with and without flooding). In all populations, by means of simple correlations, the selection of more productive plants can be accomplished by indirect selection for NGE, GWE and NFT. Through path analysis, it was possible to identify an indirect effect on GY by NGE. Also, the effect of GWE, NFT, CYC and DEF on the correlation between other characters (NGE x GY, GY x WTG, DFM x GY, GY x CYC and GY x LODG), emphasizing that the NGE, GWE, NFT, $\mathrm{DEF}$ and $\mathrm{CYC}$ are the main characters to consider for increasing grain yield in wheat.

Key words: Triticum aestivum L., indirect selection, plant breeding, characters correlation

\section{Introdução}

Solos de várzea são caracterizados por apresentarem um horizonte " $A$ " raso e um horizonte "B" impermeável, o que dificulta a drenagem natural da água, mantendo-a no solo por um longo período. Isto causa prejuízos a culturas que não possuem adaptações que permitam o estabelecimento em condições de encharcamento. O país possui aproximadamente 28 milhões de hectares de solos com ocorrência de encharcamento, sendo que o cultivo de arroz irrigado por inundação é realizado apenas no Sul do país em menos de dois milhões de hectares. O restante desta área permanece em repouso, ou como pastagem, resultando em um subaproveitamento para a produção de cereais (GOMES et al., 2006). Esta grande capacidade de exploração de fronteiras agrícolas demonstra que a seleção de genótipos mais promissores e tolerantes ao estresse por encharcamento tem grande importância e se torna uma necessidade aos programas de melhoramento vegetal localizados nestas regiões. Neste sentido, a busca de constituições genéticas que possibilitem melhores relações de custo/benefício para o cultivo de trigo nestes solos é fundamental para os produtores de cereais.

A seleção de genótipos superiores tem o objetivo de identificar simultaneamente vários caracteres agronomicamente interessantes. $\mathrm{O}$ conhecimento das correlações genéticas poderá auxiliar na seleção de um genótipo mais adequado às exigências de uma agricultura voltada aos solos de várzea. A correlação simples permite avaliar a magnitude e a direção das relações entre dois caracteres, sendo útil no melhoramento genético por permitir avaliar a viabilidade do emprego da seleção indireta que, em alguns casos, pode levar a progressos genéticos mais rápidos e altamente expressivos (CRUZ; REGAZZI, 1994). Porém, esta técnica não permite avaliar as inter-relações entre dois grupos de variáveis determinados por um número maior de caracteres de importância agronômica. A maioria das correlações é explicada pelos efeitos aditivos dos genes, afetando simultaneamente dois caracteres agronômicos (VENCOVSKY; BARRIGA, 1992).

Em plantas autógamas existem diversos métodos para a obtenção de estimativas de correlação, desenvolvidos em função do delineamento experimental, das características genéticas das populações e do ambiente de cultivo (CARVALHO; LORENCETTI; BENIN, 2004). Quando utilizados em gerações segregantes, estes métodos destacamse por separar o componente genético e o ambiente por meio da avaliação dos genitores e de suas respectivas populações segregantes (PETR; FREY, 1966; KUREK et al., 2002). Portanto, a investigação dos fatores genéticos relacionados às proporções de correlação entre caracteres é importante para se verificar a possibilidade de resposta à seleção nas gerações seguintes de condução. Contudo o efeito de um terceiro caráter, ou grupo de caracteres, pode resultar em uma correlação de alta magnitude entre dois caracteres de forma indireta (CRUZ; REGAZZI, 1994). 
O estudo da correlação de caracteres avaliados em dois sistemas diferentes de cultivo, neste caso da presença e ausência de encharcamento, possibilita uma melhor compreensão das relações específicas entre caracteres determinadas pelas diferenças fenotípicas das plantas avaliadas. A correlação entre os componentes do rendimento de grãos e de caracteres relacionados ao ciclo de desenvolvimento e à tolerância ao acamamento é muito importante para o melhoramento genético de plantas, pois, ao se efetuar a seleção com base em um caráter, resulta em alterações sobre outros caracteres de importância agronômica, correlacionados entre si (SANTOS; VENCOVSKY, 1986).

Para melhor entender a associação entre caracteres, utiliza-se o método denominado análise de trilha, que desdobra as correlações estimadas em efeitos diretos e indiretos de cada caráter sobre uma variável básica (WRIGHT, 1921). Este método baseia-se na avaliação do efeito de uma variável independente $(\mathrm{x})$ sobre uma variável dependente (y), após a remoção da influência de todas as outras variáveis independentes $\left(\mathrm{x}_{\mathrm{i}}\right)$ incluídas na análise.

Os objetivos deste trabalho consistiram em obter estimativas de coeficientes de correlação fenotípica, genotípica e ambientais e avaliar os desdobramentos das correlações genotípicas em efeitos diretos e indiretos de variáveis agronômicas sobre a variável PGP por meio da análise de dois ambientes de cultivo em quinze populações segregantes de trigo.

\section{Material e Métodos}

O experimento foi instalado no ano agrícola de 2010, no Centro Agropecuário da Palma, na área experimental do Centro de Genômica e Fitomelhoramento - FAEM/UFPel, localizado no município de Capão do Leão (RS). O município está situado a $31^{\circ} 52^{\prime}$ 00" de latitude Sul e 52²1'24" de longitude Oeste, a uma altitude de 13,24m, sendo o clima do tipo $\mathrm{Cfa}$, com uma precipitação pluviométrica média anual de 1280,2mm (MORENO, 1961). O solo da área experimental pertence à unidade de mapeamento Pelotas, classificado como Argissolo Vermelho Amarelo Distrófico (EMBRAPA, 2006).

Foram utilizados para os experimentos seis genótipos genitores FUNDACEP 29 (da Fundação Centro de Experimentação e Pesquisa FUNDACEP), IPR 85 (do Instituto Agronômico do Paraná - IAPAR), OCEPAR 11-JURITI (da Cooperativa Central de Pesquisa Agrícola COODETEC), SAFIRA (da OR Melhoramento de Sementes Ltda), BRS FIGUEIRA e BRS 117 (da EMBRAPA Trigo) e 15 populações segregantes em $\mathrm{F}_{4}$ de trigo. Os genitores foram escolhidos devido às suas diferenças sobre o caráter afilhamento e seus potenciais agronômicos. As plantas das cultivares FUNDACEP 29, IPR 85 e OCEPAR 11-JURITI têm um baixo número de afilhos, ao contrário das plantas das cultivares SAFIRA, BRS FIGUEIRA e BRS 117, portadoras de um grande número de afilhos. Tais genótipos foram submetidos a hibridações controladas, conforme modelo dialélico completo sem os recíprocos, resultando em 15 combinações híbridas.

Os tratos culturais foram realizados de acordo com as recomendações técnicas para a cultura do trigo (RCBPTT, 2010), sendo a adubação de base realizada na mesma data do transplante das plântulas, com uma dosagem de $350 \mathrm{~kg} \mathrm{ha}^{-1}$, de adubo comercial com formulação 10-20-20 (N, P e $\mathrm{K})$. A semeadura foi realizada em casa de vegetação em bandejas de germinação (um genótipo por bandeja), vinte dias antes do transplante das plântulas. A adubação de cobertura foi realizada em duas repetições totalizando $60 \mathrm{~kg} \mathrm{ha}^{-1}$ de $\mathrm{N}$, cada uma com metade da quantidade recomendada de ureia para a cultura. A primeira, dez dias antes e a segunda logo após a indução do encharcamento sob as plantas.

O delineamento experimental utilizado foi o de blocos casualizados com duas repetições, cada parcela constituída por 3 linhas de $3 \mathrm{~m}$ com plantas espaçadas a 0,20 m entre e dentro da linha, sendo 
avaliadas trinta plantas por parcela. O número total de tratamentos foi de 21 , os seis genitores e as 15 populações segregantes em cada bloco.

Os ambientes testados foram dois: com encharcamento e sem encharcamento, o estresse foi realizado do início do afilhamento ao início do florescimento, totalizando vinte dias. As plantas foram avaliadas no período anterior ao encharcamento, posterior e ao final do ciclo. Dados relativos ao florescimento e maturação foram avaliados no decorrer do cultivo. As avaliações foram realizadas no mesmo período para os dois ambientes.

Foram avaliados os seguintes caracteres: i) peso de grãos por espiga (PGE), realizado em balança de precisão com a avaliação dos grãos de uma espiga por planta, ii) número de grãos por espiga (NGE), com a contagem dos grãos de uma espiga por planta, iii) rendimento de grãos por planta $(\mathrm{RG})$, realizado em balança de precisão com a massa dos grãos de cada planta, iv) massa de mil grãos (MMG), aferido em balança de precisão, pela massa de cem grãos de cada planta, multiplicados por dez, v) número de afilhos férteis (NAF), com a contagem do número de afilhos em todas as plantas, vi) dias da emergência ao florescimento (DEF), pela diferença das datas de emergência e de florescimento (50\% mais uma planta com espigas emitidas na linha), vii) dias do florescimento à maturação (DFM), pela diferença das datas de florescimento e maturação fisiológica (50\% mais uma planta em maturação fisiológica na linha) viii) ciclo total de desenvolvimento (CICLO), dado pelo somatório de dias de DEF com DFM, e ix) acamamento (ACAM), aferido a campo em porcentagem de ocorrência para cada linha de plantas.

As correlações genéticas foram estimadas pelo programa GENES (CRUZ, 2006), utilizando o desdobramento de correlações fenotípicas, genotípicas e de ambiente descritas por Steel e Torrie (1960). Para determinar a existência de correlação linear significativa entre duas variáveis, foi utilizado o teste de boostrap com mil (1000) simulações, verificando a significância entre os valores de correlação. A análise de trilha foi realizada a partir da matriz de correlações genotípicas, considerando o caráter rendimento de grãos por planta como a variável dependente, e peso de grãos por espiga, número de grãos por espiga, massa de mil grãos, número de afilhos férteis, dias da emergência ao florescimento, dias do florescimento à maturação, ciclo total de desenvolvimento e acamamento, como variáveis explicativas GENES (CRUZ, 2006). Após identificada a presença de elevado grau de multicolinearidade, procedeu-se a análise de trilha sob multicolinearidade (análise de trilha em crista), com acréscimo de um valor $\mathrm{k}$ aos elementos da diagonal da matriz de correlação (CRUZ; CARNEIRO, 2006).

\section{Resultados e Discussão}

Pela análise de variância verificaram-se diferenças significativas para a interação entre ambientes e genótipos para todos os caracteres avaliados (dados não mostrados). Os coeficientes de correlações fenotípicas $\left(r_{p}\right)$, genotípicas $\left(r_{g}\right)$ e de ambiente $\left(\mathrm{r}_{\mathrm{e}}\right)$ revelaram que existem diferenças tanto na magnitude, como no sentido das correlações entre os caracteres estudados nos dois ambientes, para as populações segregantes avaliadas (Tabela 1). Essa diferença pode ser atribuída a efeitos do ambiente de cultivo e aos diferentes mecanismos fisiológicos que controlam a expressão desses caracteres (CARVALHO; LORENCETTI; BENIN, 2004). Em ambos os ambientes de cultivo, os coeficientes de $\mathrm{r}_{\mathrm{g}}$ mostraram ser, em sua maioria, superiores aos coeficientes de $r_{p}$. Resultados também verificados por Hartwig et al. (2007) e Silva, Carvalho e Nedel (2005) em trigo, por Benin et al. (2005) em aveia, e Moro et al. (1992), Taware, Halvankar e Raut, (1997) e Lopes et al. (2002) em soja. Essa maior magnitude nas $r_{g}$ podem ser justificadas pelo resultado dos efeitos do ambiente na associação entre os caracteres (GONÇALVES; MARTINS; BORTOLLETO, 1996), principalmente quando cultivados sob diferentes ambientes de cultivo. 
Tabela 1. Coeficientes de correlações fenotípicas $\left(r_{p}\right)$, genotípicas $\left(r_{g}\right)$ e de ambiente $\left(r_{e}\right)$ entre caracteres avaliados em dois ambientes, sem encharcamento (acima da diagonal) e com encharcamento (abaixo da diagonal) sob quinze cruzamentos e seis genitores de trigo. CGF/FAEM/UFPel. Pelotas/RS, 2011.

\begin{tabular}{|c|c|c|c|c|c|c|c|c|c|c|}
\hline Caráter & & PGE & NGE & RG & MMG & NAF & DEF & DFM & CICLO & ACAM \\
\hline \multirow[t]{3}{*}{ PGE } & $r_{p}$ & -- & $0.71 * *$ & $0.70 * *$ & $0.38^{\mathrm{ns}}$ & $0.38^{\mathrm{ns}}$ & $0.05^{\mathrm{ns}}$ & $0.38^{\mathrm{ns}}$ & $0.38^{\mathrm{ns}}$ & $-0.47^{*}$ \\
\hline & $r_{g}^{p}$ & -- & $0.71 * *$ & $0.81 * *$ & $0.29^{\mathrm{ns}}$ & $0.46^{*}$ & $0.06^{\mathrm{ns}}$ & $0.46^{*}$ & $0.46^{*}$ & $-0.55^{* *}$ \\
\hline & $r_{e}^{g}$ & -- & $0.71 * *$ & $0.25^{\mathrm{ns}}$ & $0.63 * *$ & $0.04^{\mathrm{ns}}$ & $-0.03^{\text {ns }}$ & $-0.06^{\mathrm{ns}}$ & $-0.08^{\mathrm{ns}}$ & $0.11^{\mathrm{ns}}$ \\
\hline \multirow[t]{3}{*}{ NGE } & $\mathrm{r}_{\mathrm{n}}$ & $0.88 * *$ & - & $0.75^{* *}$ & $-0.37^{\mathrm{ns}}$ & $0.68 * *$ & $0.53^{*}$ & $0.14^{\mathrm{ns}}$ & $0.59 * *$ & $-0.64 * *$ \\
\hline & $r_{g}^{p}$ & $0.89 * *$ & -- & $0.83 * *$ & $-0.47 *$ & $0.76^{* *}$ & $0.58 * *$ & $0.16^{\mathrm{ns}}$ & $0.66 * *$ & $-0.71 * *$ \\
\hline & $\begin{array}{r}r_{e}^{g} \\
r_{e}\end{array}$ & $0.82 * *$ & -- & $0.20^{\mathrm{ns}}$ & $-0.04^{\mathrm{ns}}$ & $0.09^{\mathrm{ns}}$ & $0.04^{\mathrm{ns}}$ & $-0.10^{\mathrm{ns}}$ & $-0.04^{\mathrm{ns}}$ & $0.09^{\mathrm{ns}}$ \\
\hline \multirow[t]{3}{*}{$\mathrm{RG}$} & $r_{n}$ & $0.57 * *$ & $0.64 * *$ & -- & $-0.02^{\mathrm{ns}}$ & $0.87 * *$ & $0.48 *$ & $0.25^{\text {ns }}$ & $0.65 * *$ & $-0.71 * *$ \\
\hline & $\begin{array}{l}\mathrm{p}_{\mathrm{g}} \\
\mathrm{r}^{2}\end{array}$ & $0.57 * *$ & $0.89 * *$ & -- & $-0.05^{\text {ns }}$ & $0.88 * *$ & $0.52 *$ & $0.27^{\mathrm{ns}}$ & $0.69 * *$ & $-0.74 * *$ \\
\hline & $r_{e}^{g}$ & $0.55 * *$ & $0.48^{*}$ & -- & $0.12^{\mathrm{ns}}$ & $0.72 * *$ & $-0.08^{\mathrm{ns}}$ & $0.03^{\mathrm{ns}}$ & $-0.05^{\text {ns }}$ & $-0.07^{\text {ns }}$ \\
\hline \multirow[t]{3}{*}{ MMG } & $r_{n}$ & $0.48^{*}$ & $0.02^{\mathrm{ns}}$ & $0.10^{\text {ns }}$ & -- & $-0.33^{\text {ns }}$ & $-0.64 * *$ & $0.38^{\text {ns }}$ & $-0.23^{\text {ns }}$ & $0.18^{\mathrm{ns}}$ \\
\hline & $r_{g}^{p}$ & $0.45^{*}$ & $-0.01^{\mathrm{ns}}$ & $0.07^{\mathrm{ns}}$ & -- & $-0.39^{\text {ns }}$ & $-0.75^{* *}$ & $0.45^{*}$ & $-0.27^{\mathrm{ns}}$ & $0.21^{\mathrm{ns}}$ \\
\hline & $r_{e}^{g}$ & $0.62 * *$ & $0.11^{\mathrm{ns}}$ & $0.27^{\mathrm{ns}}$ & -- & $-0.04^{\text {ns }}$ & $-0.09^{\text {ns }}$ & $0.03^{\mathrm{ns}}$ & $-0.06^{\text {ns }}$ & $0.14^{\mathrm{ns}}$ \\
\hline \multirow[t]{3}{*}{ NAF } & $r_{p}$ & $0.09^{\text {ns }}$ & $0.28^{\mathrm{ns}}$ & $0.79 * *$ & $-0.30^{\mathrm{ns}}$ & -- & $0.55 * *$ & $0.14^{\mathrm{ns}}$ & $0.61 * *$ & $-0.71^{* *}$ \\
\hline & $\mathrm{r}_{\mathrm{g}}$ & $0.06^{\mathrm{ns}}$ & $0.27^{\mathrm{ns}}$ & $0.80 * *$ & $-0.38^{\mathrm{ns}}$ & -- & $0.58 * *$ & $0.14^{\text {ns }}$ & $0.64 * *$ & $-0.73 * *$ \\
\hline & $r_{e}^{8}$ & $0.41^{\mathrm{ns}}$ & $0.40^{\mathrm{ns}}$ & $0.78 * *$ & $0.15^{\mathrm{ns}}$ & -- & $-0.09^{\text {ns }}$ & $0.06^{\mathrm{ns}}$ & $-0.04^{\mathrm{ns}}$ & $-0.18^{\mathrm{ns}}$ \\
\hline \multirow[t]{3}{*}{$\mathrm{DEF}$} & $r_{p}$ & $0.18^{\mathrm{ns}}$ & $0.35^{\text {ns }}$ & $0.47^{*}$ & $-0.30^{\text {ns }}$ & $0.58 * *$ & -- & $-0.35^{\text {ns }}$ & $0.58 * *$ & $-0.55 * *$ \\
\hline & $r_{g}^{p}$ & $0.18^{\mathrm{ns}}$ & $0.38^{\mathrm{ns}}$ & $0.50 *$ & $-0.39^{\text {ns }}$ & $0.61 * *$ & -- & $-0.35^{\mathrm{ns}}$ & $0.57 * *$ & $-0.56^{* *}$ \\
\hline & $r_{e}$ & $0.19^{\mathrm{ns}}$ & $0.09^{\text {ns }}$ & $0.08^{\mathrm{ns}}$ & $0.24^{\mathrm{ns}}$ & $0.07^{\mathrm{ns}}$ & -- & $-0.31^{\mathrm{ns}}$ & $0.70 * *$ & $-0.01^{\mathrm{ns}}$ \\
\hline \multirow[t]{3}{*}{ DFM } & $\begin{array}{l}e \\
r_{p}\end{array}$ & $0.12^{\text {ns }}$ & $-0.14^{\text {ns }}$ & $0.01^{\mathrm{ns}}$ & $0.49 *$ & $-0.16^{\mathrm{ns}}$ & $-0.61 * *$ & -- & $0.56^{* *}$ & $-0.35^{\mathrm{ns}}$ \\
\hline & $r_{g}^{p}$ & $0.12^{\mathrm{ns}}$ & $-0.15^{\mathrm{ns}}$ & $0.01^{\mathrm{ns}}$ & $0.56^{* *}$ & $-0.17^{\mathrm{ns}}$ & $-0.63 * *$ & -- & $0.56 * *$ & $-0.36^{\mathrm{ns}}$ \\
\hline & $r_{e}^{g}$ & $0.11^{\mathrm{ns}}$ & $0.10^{\mathrm{ns}}$ & $-0.07^{\mathrm{ns}}$ & $0.02^{\mathrm{ns}}$ & $0.03^{\mathrm{ns}}$ & $-0.15^{\mathrm{ns}}$ & -- & $0.46^{*}$ & $0.07^{\mathrm{ns}}$ \\
\hline \multirow[t]{3}{*}{ CICLO } & $r_{p}$ & $0.34^{\mathrm{ns}}$ & $0.28^{\mathrm{ns}}$ & $0.57 * *$ & $0.14^{\mathrm{ns}}$ & $0.54 * *$ & $0.58 * *$ & $0.29^{\mathrm{ns}}$ & -- & $-0.79 * *$ \\
\hline & $\mathrm{r}_{\mathrm{g}}^{\mathrm{p}}$ & $0.35^{\text {ns }}$ & $0.30^{\text {ns }}$ & $0.63 * *$ & $0.13^{\text {ns }}$ & $0.57 * *$ & $0.55^{* *}$ & $0.30^{\text {ns }}$ & -- & $-0.80 * *$ \\
\hline & $r_{e}^{g}$ & $0.23^{\mathrm{ns}}$ & $0.13^{\mathrm{ns}}$ & $0.05^{\text {ns }}$ & $0.24^{\mathrm{ns}}$ & $0.08^{\mathrm{ns}}$ & $0.93 * *$ & $0.23^{\mathrm{ns}}$ & -- & $0.05^{\text {ns }}$ \\
\hline \multirow[t]{3}{*}{ ACAM } & $r_{p}$ & $-0.32^{\text {ns }}$ & $-0.21^{\mathrm{ns}}$ & $-0.54 * *$ & $-0.24^{\mathrm{ns}}$ & $-0.45^{*}$ & $-0.42^{\text {ns }}$ & $-0.32^{\mathrm{ns}}$ & $-0.84^{* *}$ & -- \\
\hline & $\begin{array}{l}\mathrm{p} \\
\mathrm{r}_{\mathrm{g}}\end{array}$ & $-0.35^{\text {ns }}$ & $-0.22^{\mathrm{ns}}$ & $-0.57 * *$ & $-0.28^{\mathrm{ns}}$ & $-0.46^{*}$ & $-0.43^{*}$ & $-0.33^{\mathrm{ns}}$ & $-0.87 * *$ & -- \\
\hline & $r^{g}$ & $-0.10^{\mathrm{ns}}$ & $-0.08^{\text {ns }}$ & $-0.12^{\mathrm{ns}}$ & $-0.04^{\mathrm{ns}}$ & $-0.20^{\mathrm{ns}}$ & $-0.14^{\mathrm{ns}}$ & $0.05^{\mathrm{ns}}$ & $-0.12^{\text {ns }}$ & -- \\
\hline
\end{tabular}

Índices de correlações, ns, “***” e “*” não significativo e significativo a $1 \%$ e $5 \%$ de probabilidade pelo teste t, respectivamente, sobre os caracteres peso de grãos por espiga (PGE), número de grãos por espiga (NGE), rendimento de grãos (RG), massa de mil grãos (MMG), número de afilhos férteis (NAF), dias de emergência ao florescimento (DEF), dias do florescimento à maturação (DFM), ciclo (CICLO) e acamamento (ACAM).

Fonte: Elaboração dos autores.

Alguns coeficientes apresentaram significância mesmo tendo baixas magnitudes, este fato está associado ao elevado número de graus de liberdade incluídos no teste $\mathrm{t}$ (VASCONCELLOS et al., 1998). Por este motivo, existe uma tendência dos pesquisadores no melhoramento de plantas, a valorizarem mais o sinal (positivo ou negativo) e a magnitude dos valores na interpretação das correlações. Assim, é usual adotar como critério de discussão, valores de estimativas abaixo de $-0,50$ e acima de 0,50 (LOPES et al., 2002). Neste trabalho, quando possível, este critério também foi utilizado na discussão dos resultados.

O efeito de ambiente foi contrastante em relação ao sentido da magnitude das correlações. No entanto, em sua maioria foram negativas, assim como observado por Kurek et al. (2002), Benin et al. (2005) em aveia branca e Hartwig et al. (2007) em trigo. Correlações significativas e positivas para o ambiente sem encharcamento foram observadas entre PGE e NGE $\left(\mathrm{r}_{\mathrm{e}}=0,71\right)$, PGE e MMG $\left(\mathrm{r}_{\mathrm{e}}=\right.$ $0,63)$, RG e NAF $\left(r_{e}=0,72\right)$ e entre DEF e CICLO 
$\left(r_{e}=0,70\right)$, assim como para o ambiente com encharcamento entre NGE e PGE $\left(r_{e}=0,82\right)$, RG e PGE $\left(r_{e}=0,55\right)$, MMG e PGE $\left(r_{e}=0,620\right)$, NAF e $R G\left(r_{e}=0,78\right)$ e entre CICLO e DEF $\left(r_{e}=0,93\right)$. O valor das correlações entre caracteres foi alterado quando comparados os ambientes (com e sem encharcamento), contudo as mesmas correlações que foram significativas no ambiente estressado também são observadas no ambiente sem estresse. As correlações de ambiente são apontadas como o ambiente favorecendo um caráter em detrimento do outro. Valores positivos de correlação de ambiente indicam que ambos os caracteres foram prejudicados ou beneficiados pelas mesmas variações de ambiente (FALCONER, 1987).

Caracteres com elevada magnitude de correlação (fenotípica e genotípica) podem ser considerados nas estratégias de seleção (CRUZ; REGAZZI, 1994). Desse modo, uma estratégia que pode ser adotada de acordo com o método de condução das populações deste trabalho, e com base nos resultados obtidos nas populações segregantes dos cruzamentos avaliados, é a seleção indireta positiva por meio do peso de grãos por espiga, do número de grãos por espiga, do número de afilhos férteis por planta, do dia da emergência ao florescimento e do ciclo de desenvolvimento da cultura, e negativo com o acamamento para a obtenção de plantas mais produtivas, tendo em vista as correlações obtidas entre os caracteres.

Algumas correlações se mantiveram significativas para os dois ambientes de cultivo, sendo que para o ambiente sem encharcamento os valores foram de $\left(r_{p}=0,71\right.$ e $\left.r_{g}=0,71\right)$ para PGE $x$ NGE, de $\left(r_{p}=0,70\right.$ e $\left.r_{g}=0,81\right)$ para PGE x RG, de $\left(r_{p}=0,75\right.$ e $\left.r_{g}=0,83\right)$ para NGE $x$ RG, de $\left(r_{p}=\right.$ 0,87 e $\left.r_{g}=0,88\right)$ para RG x NAF, de $\left(r_{p}=0,48\right.$ e $r_{g}$ $=0,52)$ para $R G \times D E F$, de $\left(r_{p}=0,65\right.$ e $\left.r_{g}=0,69\right)$ para RG x CICLO, de $\left(r_{p}=-0,71\right.$ e $\left.r_{g}=-0,74\right)$ para RG x ACAM, de $\left(r_{p}=0,55\right.$ e $\left.r_{g}=0,58\right)$ para NAF $x$ DEF, de $\left(r_{p}=0,61\right.$ e $\left.r_{g}=0,64\right)$ para NAF x CICLO, de $\left(r_{p}=-0,71\right.$ e $\left.r_{g}=-0,73\right)$ para NAF x ACAM, de $\left(r_{p}=0,58\right.$ e $\left.r_{g}=0,57\right)$ para DEF x CICLO, de $\left(r_{p}=\right.$
$-0,55$ e $\left.\mathrm{r}_{\mathrm{g}}=-0,56\right)$ para DEF $\mathrm{x}$ ACAM e de $\left(\mathrm{r}_{\mathrm{p}}=\right.$ $-0,79$ e $\left.r_{g}=-0,80\right)$ para CICLO x ACAM. Para os blocos conduzidos com encharcamento os valores foram de $\left(r_{p}=0,88\right.$ e $\left.r_{g}=0,89\right)$ para PGE x NGE, de $\left(r_{p}=0,57\right.$ e $\left.r_{g}=0,57\right)$ para PGE $x$ RG, de $\left(r_{p}=\right.$ 0,64 e $\left.r_{g}=0,89\right)$ para NGE x RG, de $\left(r_{p}=0,79\right.$ e $r_{g}$ $=0,80)$ para $R G \times$ NAF, de $\left(r_{p}=0,47\right.$ e $\left.r_{g}=0,50\right)$ para $R G \times D E F$, de $\left(r_{p}=0,57\right.$ e $\left.r_{g}=0,63\right)$ para $R G$ x CICLO, de $\left(r_{p}=-0,54\right.$ e $\left.r_{g}=-0,57\right)$ para $R G x$ ACAM, de $\left(r_{p}=0,58\right.$ e $\left.r_{g}=0,61\right)$ para NAF x DEF, de $\left(r_{p}=0,54\right.$ e $\left.r_{g}=0,57\right)$ para NAF $x$ CICLO, de $\left(r_{p}\right.$ $=-0,45$ e $\left.r_{\mathrm{g}}=-0,46\right)$ para NAF $\times$ ACAM, de $\left(r_{p}=\right.$ 0,58 e $\left.r_{g}=0,55\right)$ para DEF x CICLO, de $\left(r_{p}=-0,42\right.$ e $\left.r_{g}=-0,43\right)$ para DEF $x$ ACAM e de $\left(r_{p}=-0,84\right.$ e $r_{g}$ $=-0,87)$ para CICLO x ACAM. Estes coeficientes indicam que a seleção de plantas com maior número de afilhos, maior número de grãos por espiga e com maior massa de grãos por espiga resultará em genótipos mais produtivos. Todavia, a utilização de métodos de seleção que empregam a semeadura em plantas espaçadas, favorece um maior número de afilhos férteis por planta divergindo da condição de semeadura em linha cheia (comercial), o que pode interferir no fenótipo destes genótipos quando semeados em densidade comercial.

Correlações fenotípicas e genotípicas fortes e positivas entre NGE x NAF $\left(r_{p}=0,68\right.$ e $\left.r_{g}=0,76\right)$, NGE x DEF $\left(r_{p}=0,53\right.$ e $\left.r_{g}=0,58\right)$, NGE e CICLO $\left(r_{p}=0,59\right.$ e $\left.r_{g}=0,66\right)$, DFM e CICLO $\left(r_{p}=0,56\right.$ e $\left.r_{g}=0,56\right)$ e negativas entre PGE e ACAM $\left(r_{p}=\right.$ $-0,47$ e $\left.r_{g}=-0,55\right)$, NGE e ACAM $\left(r_{p}=-0,64\right.$ e $r_{g}$ $=-0,71)$ e MMG e DEF $\left(r_{p}=-0,64\right.$ e $\left.r_{g}=-0,75\right)$ foram observadas apenas para os blocos conduzidos sem encharcamento, indicando que o estresse influenciou na manutenção destes coeficientes.

$\mathrm{O}$ caráter NAF manteve correlações significativas e positivas de forte magnitude para coeficientes fenotípicos e genotípicos no ambiente sem encharcamento com NGE $\left(r_{p}=0,68\right.$ e $r_{g}=$ $0,76), \mathrm{RG}\left(\mathrm{r}_{\mathrm{p}}=0,87\right.$ e $\left.\mathrm{r}_{\mathrm{g}}=0,88\right), \operatorname{DEF}\left(\mathrm{r}_{\mathrm{p}}=0,55\right.$ e $\left.r_{g}=0,58\right)$ e CICLO $\left(r_{p}=0,61\right.$ e $\left.r_{g}=0,64\right)$ e negativa com ACAM $\left(r_{p}=-0,71\right.$ e $\left.r_{g}=-0,73\right)$. Para o ambiente encharcado o NAF manteve correlações 
significativas e positivas com $R G\left(r_{p}=0,79\right.$ e $r_{g}=$ $0,80), \operatorname{DEF}\left(r_{p}=0,58\right.$ e $\left.r_{g}=0,61\right)$ e CICLO $\left(r_{p}=0,54\right.$ e $\left.r_{g}=0,57\right)$ e negativa com ACAM $\left(r_{p}=-0,45\right.$ e $r_{g}$ $=-0,46)$. Portanto, as significâncias das correlações com o NAF mantiveram-se entre os dois ambientes, modificando apenas sua magnitude. Tais correlações indicam que genótipos com maior período de desenvolvimento vegetativo e com maior ciclo propiciam o desenvolvimento de maior número de afilhos por planta e que quanto maior o número de afilhos menor a ocorrência de acamamento nas plantas. Estes resultados concordam com os obtidos por Walton (1971), Camargo, Ferreira Filho e Felicio (1998), Okuyama, Federizzi e Brabosa Neto (2004), Silva, Carvalho e Nedel (2005) e Hartwig et al. (2007).

Os caracteres DEF $\mathrm{x}$ CICLO mantiveram correlações significativas e positivas para os blocos sem encharcamento $\left(r_{p}=0,58, r_{g}=0,57\right.$ e $\left.r_{e}=0,70\right)$ e com encharcamento $\left(r_{p}=0,58, r_{g}=0,55\right.$ e $r_{e}=$ $0,93)$, indicando que o ciclo de desenvolvimento do trigo está diretamente relacionado ao período de desenvolvimento vegetativo das plantas. O caráter CICLO manteve correlações significativas e negativas de alta magnitude com ACAM tanto no ambiente sem encharcamento $\left(r_{p}=-0,79, r_{g}=\right.$ $-0,80$ e $\left.r_{e}=-0,05\right)$ como com encharcamento $\left(r_{p}\right.$ $=-0,84, r_{\mathrm{g}}=-0,87$ e $\left.\mathrm{r}_{\mathrm{e}}=-0,12\right)$, indicando que genótipos de ciclo precoce são mais suscetíveis ao acamamento que genótipos com ciclo tardio, contudo a seleção de plantas mais baixas e precoces pode interferir nestes resultados visto que plantas mais baixas tendem a ter menor acamamento devido ao aumento da espessura do colmo. Plantas com maior número de afilhos também possuem menor índice de acamamento, com isso a seleção de plantas com maior número de afilhos pode estar associada à seleção de plantas mais precoces para diminuir o efeito do acamamento. A seleção de plantas mais precoces deverá levar em consideração os demais caracteres envolvidos com a tolerância ao acamamento.

Correlações positivas entre número de grãos por espiga e massa de grãos por espiga, e desta com massa média de mil grãos em populações segregantes de trigo foram relatadas (CAMARGO; FERREIRA FILHO; FELICIO, 1998), sugerindo uma grande importância dessas correlações no melhoramento de trigo. No presente trabalho, o caráter NGE revelou ter uma boa relevância entre as $r_{p}$ e $r_{g}$ de magnitudes consideráveis com o caráter PGE e com RG em todos os cruzamentos, em ambos os ambientes. Esse fato corrobora com a seleção indireta sobre o caráter NGE, visto que atua no sentido de incrementar o número de grãos por espiga, consequentemente aumenta a massa de grãos e ainda está correlacionado com a massa média de mil grãos, promovendo ganhos para esse caráter. Resultados semelhantes foram obtidos por Hartwig et al. (2007).

Com o estudo mais detalhado das associações obtidas pela análise de trilha, verifica-se que as relações entre a produção de grãos por planta, com seus componentes e outros caracteres são pouco diferentes daqueles observados na análise de correlações simples. Assim, o desdobramento das correlações em efeitos direto e indireto justifica as correlações positivas e negativas, de altas e baixas magnitudes entre os caracteres estudados.

Pela análise de multicolinearidade dos dados, usando o teste de auto-valores e autovetores da matriz de correlação genotípica nas variáveis independentes do modelo, observouse multicolinearidade severa. Utilizou-se a metodologia denominada análise de trilha em crista, para estimação dos parâmetros como forma alternativa à metodologia dos quadrados mínimos. A constante $\mathrm{k}$ adicionada à diagonal da matriz $\mathrm{X}^{\prime} \mathrm{X}$ foi determinada pelo exame do traço da crista para cada tratamento, por meio da construção de um gráfico onde foram plotados os coeficientes de trilha em razão dos valores de $\mathrm{k}$ no intervalo de $0<\mathrm{k}<$ 1 (CARVALHO, 1995). A constante $\mathrm{k}$ determinada pelo exame do traço da crista, adotada para o ambiente não encharcado foi de 0,1479 e para o ambiente encharcado foi de 0,1002 . 
O coeficiente de determinação do modelo da análise de trilha obteve alta magnitude, com valor de 0,9717 para o ambiente não encharcado e de 0,8660 para o ambiente encharcado, indicando que as variáveis independentes consideradas no estudo, explicaram uma grande fração da variação observada no diagrama causal, para o caráter dependente rendimento de grãos (Tabela 2).

Tabela 2. Estimativas dos efeitos diretos e indiretos dos coeficientes da análise de trilha, estimados a partir da correlação genética, sobre o rendimento médio de grãos por espiga em dois ambientes de cultivo (encharcado e não encharcado) de quinze cruzamentos e seis genitores de trigo. CGF/FAEM/UFPel. Pelotas/RS, 2011.

\begin{tabular}{|c|c|c|c|}
\hline \multirow{2}{*}{ Caráter } & \multirow{2}{*}{ Vias de associação } & \multicolumn{2}{|c|}{ Coeficiente de trilha } \\
\hline & & Não encharcado & Encharcado \\
\hline \multirow[t]{9}{*}{ PGE } & Efeito direto sobre RG & 0.2790 & 0.1463 \\
\hline & Efeito indireto via NGE & 0.1641 & 0.2425 \\
\hline & Efeito indireto via $\mathrm{MMG}$ & 0.1037 & 0.0979 \\
\hline & Efeito indireto via NAF & 0.2150 & 0.0430 \\
\hline & Efeito indireto via DEF & 0.0153 & 0.0014 \\
\hline & Efeito indireto via DFM & -0.0395 & 0.0007 \\
\hline & Efeito indireto via CICLO & 0.0635 & 0.0049 \\
\hline & Efeito indireto via ACAM & -0.0307 & 0.0220 \\
\hline & Total $\left(\mathrm{r}_{\mathrm{g}}\right)$ & 0.8116 & 0.5734 \\
\hline \multirow[t]{9}{*}{ NGE } & Efeito direto sobre $\mathrm{RG}$ & 0.2304 & 0.2719 \\
\hline & Efeito indireto via PGE & 0.1987 & 0.1305 \\
\hline & Efeito indireto via $\mathrm{MMG}$ & -0.1664 & -0.0003 \\
\hline & Efeito indireto via NAF & 0.3578 & 0.1856 \\
\hline & Efeito indireto via DEF & 0.1426 & 0.0030 \\
\hline & Efeito indireto via DFM & -0.014 & -0.0009 \\
\hline & Efeito indireto via CICLO & 0.0914 & 0.0041 \\
\hline & Efeito indireto via ACAM & -0.0393 & 0.0143 \\
\hline & Total $\left(\mathrm{r}_{\mathrm{g}}\right)$ & 0.8351 & 0.6354 \\
\hline \multirow[t]{9}{*}{ MMG } & Efeito direto sobre $\mathrm{RG}$ & 0.3561 & 0.2179 \\
\hline & Efeito indireto via PGE & 0.0812 & 0.0658 \\
\hline & Efeito indireto via NGE & -0.1076 & -0.0004 \\
\hline & Efeito indireto via NAF & -0.184 & -0.258 \\
\hline & Efeito indireto via DEF & -0.1836 & -0.0031 \\
\hline & Efeito indireto via DFM & -0.0386 & 0.0034 \\
\hline & Efeito indireto via CICLO & -0.0375 & 0.0018 \\
\hline & Efeito indireto via ACAM & 0.0116 & 0.0178 \\
\hline & Total $\left(\mathrm{r}_{\mathrm{g}}\right)$ & -0.0498 & 0.0669 \\
\hline \multirow[t]{9}{*}{ NAF } & Efeito direto sobre $\mathrm{RG}$ & 0.4695 & 0.6852 \\
\hline & Efeito indireto via PGE & 0.1277 & 0.0092 \\
\hline & Efeito indireto via NGE & 0.1755 & 0.0736 \\
\hline & Efeito indireto via $\mathrm{MMG}$ & -0.1396 & -0.0820 \\
\hline & Efeito indireto via DEF & 0.1416 & 0.0049 \\
\hline & Efeito indireto via DFM & -0.0121 & -0.0010 \\
\hline & Efeito indireto via CICLO & 0.0882 & 0.0080 \\
\hline & Efeito indireto via ACAM & -0.0406 & 0.0292 \\
\hline & Total $\left(r_{q}\right)$ & 0.8796 & 0.7959 \\
\hline
\end{tabular}


continuação

\begin{tabular}{|c|c|c|c|}
\hline \multirow{9}{*}{ DEF } & Efeito direto sobre RG & 0.2442 & 0.0080 \\
\hline & Efeito indireto via PGE & 0.0175 & 0.0263 \\
\hline & Efeito indireto via NGE & 0.1346 & 0.1026 \\
\hline & Efeito indireto via $\mathrm{MMG}$ & -0.2678 & -0.0839 \\
\hline & Efeito indireto via NAF & 0.2723 & 0.4196 \\
\hline & Efeito indireto via DFM & 0.0304 & -0.0038 \\
\hline & Efeito indireto via CICLO & 0.0795 & 0.0077 \\
\hline & Efeito indireto via ACAM & -0.0307 & 0.0273 \\
\hline & $\operatorname{Total}\left(\mathrm{r}_{\mathrm{o}}\right)$ & 0.5160 & 0.5042 \\
\hline \multirow[t]{9}{*}{ DFM } & Efeito direto sobre RG & -0.0860 & 0.0060 \\
\hline & Efeito indireto via PGE & 0.1281 & 0.0180 \\
\hline & Efeito indireto via NGE & 0.0376 & -0.0417 \\
\hline & Efeito indireto via $\mathrm{MMG}$ & 0.1599 & 0.1226 \\
\hline & Efeito indireto via NAF & 0.0662 & -0.1137 \\
\hline & Efeito indireto via DEF & -0.0864 & -0.0050 \\
\hline & Efeito indireto via CICLO & 0.0783 & 0.0042 \\
\hline & Efeito indireto via ACAM & -0.0197 & 0.0208 \\
\hline & $\operatorname{Total}\left(\mathrm{r}_{\mathrm{o}}\right)$ & 0.2650 & 0.0118 \\
\hline \multirow[t]{9}{*}{ CICLO } & Efeito direto sobre RG & 0.1388 & 0.0139 \\
\hline & Efeito indireto via PGE & 0.1277 & 0.0514 \\
\hline & Efeito indireto via NGE & 0.1517 & 0.081 \\
\hline & Efeito indireto via $\mathrm{MMG}$ & -0.0963 & 0.0284 \\
\hline & Efeito indireto via NAF & 0.2984 & 0.3924 \\
\hline & Efeito indireto via DEF & 0.1398 & 0.0044 \\
\hline & Efeito indireto via DFM & -0.0485 & 0.0018 \\
\hline & Efeito indireto via ACAM & -0.0444 & 0.0557 \\
\hline & Total $\left(\mathrm{r}_{\mathrm{g}}\right)$ & 0.6878 & 0.6305 \\
\hline \multirow[t]{9}{*}{ ACAM } & Efeito direto sobre $\mathrm{RG}$ & 0.0553 & -0.0637 \\
\hline & Efeito indireto via PGE & -0.1547 & -0.0506 \\
\hline & Efeito indireto via NGE & -0.1638 & -0.0609 \\
\hline & Efeito indireto via $\mathrm{MMG}$ & 0.0747 & -0.0609 \\
\hline & Efeito indireto via NAF & -0.3446 & -0.3134 \\
\hline & Efeito indireto via DEF & -0.1357 & -0.0034 \\
\hline & Efeito indireto via DFM & 0.0306 & -0.0020 \\
\hline & Efeito indireto via CICLO & -0.1114 & -0.0122 \\
\hline & Total $\left(\mathrm{r}_{\mathrm{g}}\right)$ & -0.7411 & -0.5731 \\
\hline \multicolumn{2}{|c|}{ Coeficiente de determinação } & 0.9717 & 0.8660 \\
\hline \multicolumn{2}{|c|}{ Valor de K usado na análise } & 0.1479 & 0.1002 \\
\hline \multicolumn{2}{|c|}{ Efeito da variável residual } & 0.1682 & 0.3660 \\
\hline \multicolumn{2}{|c|}{ Determinante da matriz } & 0.0134 & 0.0074 \\
\hline
\end{tabular}

Análise de trilha sobre os caracteres peso de grãos por espiga (PGE), número de grãos por espiga (NGE), rendimento de grãos (RG), massa de mil grãos (MMG), número de afilhos férteis (NAF), dias de emergência ao florescimento (DEF), dias do florescimento à maturação (DFM), ciclo (CICLO) e acamamento (ACAM).

Fonte: Elaboração dos autores. 
A relação direta entre PGE sobre $o$ RG foi mais acentuada para o bloco conduzido sem encharcamento $(0,2790)$. Assim como o efeito total mais pronunciado para a correlação $\left(r_{g}=0,8116\right)$. Efeitos indiretos positivos sobre o PGE podem ser observados no ambiente encharcado para o NGE $(0,2425)$ e para NGE, MMG e NAF $(0,1641$, 0,1037 e 0,2150 , respectivamente) para os blocos conduzidos sem encharcamento. Efeitos negativos indiretos não foram observados para este caráter.

Elevada expressão dos efeitos indiretos da correlação genotípica entre NGE e RG foram constatados mais pronunciadamente sobre os blocos conduzidos sem encharcamento (Tabela 2). Os caracteres PGE, NAF e DEF através dos seus efeitos indiretos positivos $(0,1987,0,3578$ e 0,1426 respectivamente) foram os que promoveram a $r_{\mathrm{g}}=0,835$ entre NGE e RG, visto o efeito negativo indireto da MMG (-0,1664). No ambiente encharcado o efeito direto de NGE sobre RG também foi positivo, porém de maior magnitude $(0,2719)$ sendo que os caracteres PGE, e NAF contribuíram com efeitos indiretos positivos $(0,1305$ e 0,1856 ) resultando na $r_{g}=0,635$. Grande efeito do NGE foi constatado sobre o rendimento de grãos em trigo cultivado em ambiente normal (GONDIM et al., 2008; VESOHOSKI et al., 2011), corroborando com os resultados obtidos neste trabalho.

Efeitos diretos positivos podem ser observados para MMG sobre RG (Tabela 2), para os dois ambientes de cultivo, não encharcado e encharcado (0,3561 e 0,2179). Efeitos indiretos negativos foram mais pronunciados no ambiente não encharcado para NGE, NAF e DEF $(-0,1076,-0,1840$ e -0,1836) e para NAF $(-0,2580)$ no ambiente encharcado. Para o efeito total não foram observados altas magnitudes na relação entre MMG e RG. Resultados semelhantes foram obtidos para a correlação e análise de trilha, onde a MMG apresentou grande efeito direto sobre o rendimento de grãos em trigo cultivado em ambiente normal (VESOHOSKI et al., 2011) e também quando submetido a desfolha (GONDIM et al., 2008).
Foi observada uma relação de causa e efeito no desdobramento da correlação genotípica entre NAF e RG (Tabela 2), nos dois ambientes de cultivo, não encharcado $(0,4695)$ e encharcado $(0,6852)$ onde o efeito direto de NAF sobre RG foi o promotor da correlação genotípica revelada entre eles $(0,88$ e 0,80). Segundo Vencovsky e Barriga (1992), nessas circunstâncias, a seleção direta sobre o caráter (número de afilhos férteis) será eficiente para melhorar o rendimento de grãos. Contudo o efeito indireto negativo de MMG (-0,1396 e -0,0820) e positivo via NGE $(0,1755$ e 0,0736$)$ também contribuíram com a correlação genotípica. Isto indica que plantas com maior número de afilhos, tendem a possuir maior número de grãos por espiga com menor massa. Para o melhoramento de plantas o caráter NAF, pode ser utilizado na seleção de plantas mais produtivas, porém salienta-se que o aumento do número de afilhos acarretará na diminuição da massa de mil grãos nos genótipos selecionados. Grande efeito positivo direto, do número de espigas por parcela com o rendimento de grãos e indireto do número de grãos por espiga, também foram obtidos para trigo submetido à desfolha (GONDIM et al., 2008) e em cultivo normal (OKUYAMA; FEDERIZZI; BRABOSA NETO, 2004; HARTWIG et al., 2007), corroborando com os resultados obtidos nos dois ambientes avaliados.

Efeito direto positivo entre DEF e RG foi observado para o bloco conduzido sem encharcamento $(0,2442)$ e negativo via $\mathrm{MMG}$ $(-0,2678)$ (Tabela 2). Contudo os efeitos indiretos positivos e de alta magnitude, via NGE $(0,1346)$ e $\operatorname{NAF}(0,2723)$ ajudaram a manutenção da correlação genotípica positiva $\left(\mathrm{r}_{\mathrm{g}}=0,5160\right)$. Para o ambiente encharcado o efeito indireto positivo via NAF $(0,4196)$ foi o responsável pelo valor da correlação genotípica. Os valores de correlação entre os dois ambientes foram muito próximos, porém os efeitos entre os caracteres sofreram alterações pelo estresse aplicado. Genótipos com maior número de afilhos tendem a ser mais produtivos e apresentam maior período de desenvolvimento vegetativo (HARTWIG 
et al., 2007). O estresse por encharcamento alterou as relações indiretas entre os caracteres, mas manteve a relação direta entre DEF e RG.

Apesar de os resultados mostrarem a não existência de correlação genotípica entre DFM e RG (Tabela 1) efeitos diretos e indiretos foram observados para esta relação na análise de trilha (Tabela 2). No ambiente não encharcado o efeito indireto positivo de PGE $(0,1281)$ e MMG $(0,1599)$ foi responsável pela correlação positiva. No entanto, para o ambiente encharcado, observou-se que o efeito indireto negativo de NAF $(-0,1137)$ e positivo indireto via MMG $(0,1226)$ resultaram na correlação genotípica $\left(\mathrm{r}_{\mathrm{g}}=0,012\right)$. Os efeitos indiretos dos caracteres PGE, MMG e NAF foram mais pronunciados do que a relação direta entre DFM e RG, indicando uma maior influência no rendimento de grãos do peso dos grãos por espiga, da massa de mil grãos e do número de afilhos férteis.

Foi observada correlação positiva e de alta magnitude entre os caracteres CICLO e RG para o ambiente não encharcado e encharcado $\left(r_{\mathrm{g}}=0,6878\right.$ e $\left.r_{g}=0,6305\right)$. Para o ambiente não encharcado o efeito direto e positivo de CICLO $(0,1388)$ junto com os efeitos indiretos e positivos de PGE, NGE, NAF e DEF (0,1277, 0,1517, 0,2984 e 0,1398 respectivamente) foram os responsáveis pela $r_{g}$ obtida. Para o ambiente encharcado o efeito indireto positivo de alta magnitude via NAF $(0,3924)$, foi o responsável pela $r_{g}$ total. Sendo um dos principais caracteres para seleção de genótipos em trigo, o ciclo da cultura é de suma importância para o melhoramento de plantas, visto que genótipos com maior ciclo tendem a ser mais produtivos por apresentarem, maior peso de grãos por espiga, maior número de grãos por espiga, maior número de afilhos férteis e maior desenvolvimento vegetativo.

Alterações nos efeitos diretos e indiretos entre os ambientes também foram observados para ACAM, onde os efeitos indiretos foram responsáveis pela correlação genética com RG. Para o ambiente não encharcado o efeito indireto negativo via PGE $(-0,1547)$, NGE $(-0,1638)$, NAF $(-0,3446)$, DEF $(-0,1357)$ e CICLO $(-0,1114)$ resultaram na correlação genética negativa $\left(r_{\mathrm{g}}=-\right.$ 0,7411). No ambiente encharcado todos os efeitos foram negativos, sendo o de maior magnitude o efeito indireto via NAF (-0,3134). Isto indica que o acamamento em trigo diminui o peso e o número de grãos por espiga, que genótipos mais tolerantes ao acamamento apresentam maior número de afilhos férteis e que genótipos com maior desenvolvimento vegetativo, tendem a ter menores índices de acamamento. Para o melhoramento de plantas a seleção de genótipos com maior período de desenvolvimento vegetativo e maior número de afilhos férteis promove a obtenção de linhagens mais tolerantes ao acamamento.

Esses resultados justificam a grande importância do desdobramento das correlações em coeficientes de trilha, uma vez que somente assim é possível a visualização da verdadeira associação entre os caracteres, bem como o comportamento da expressividade da contribuição direta e/ou indireta na formação da correlação genotípica (CARVALHO, 1995). Em todas as relações, diretas e indiretas, o estresse por encharcamento alterou a magnitude de relação. Os caracteres que mais contribuíram para a produção de grãos por planta foram o peso de grãos por espiga, o número de grãos por espiga, a massa de mil grãos, o número de afilhos férteis e os dias da emergência ao florescimento.

\section{Conclusões}

Os principais caracteres indicados para utilização na seleção indireta de populações de trigo visando o aumento do rendimento de grãos são NAF, PGE e NGE, devido ao alto coeficiente de correlação destes com a produção de grãos.

O estresse por encharcamento possui grande efeito sobre as correlações $\left(r_{p}, r_{g}\right.$ e $\left.r_{e}\right)$ e sobre as vias de associação direta e indireta dos caracteres RG, PGE, NGE, MMG, NAF, DEF, DFM, CICLO e ACAM em trigo. 


\section{Agradecimentos}

Os autores agradecem a CAPES, ao CNPq e à FAPERGS pela concessão de bolsas de Pósgraduação, Iniciação Científica e suporte nesta pesquisa.

\section{Referências}

BENIN, G.; CARVALHO, F. I. F.; OLIVEIRA, A. C.; HARTWIG, I.; SHCMIDT, D.; VIEIRA, E. A.; VALÉRIO, I. P.; GONZALES DA SILVA, J. Estimativas de correlações genotípicas e de ambiente em gerações com elevada freqüência de heterozigotos. Ciência Rural, Santa Maria, v. 35, n. 3, p. 523-529, 2005.

CAMARGO, C. E. O.; FERREIRA FILHO, A. W. P.; FELICIO, J. C. Herdabilidade e correlações entre características agronômicas em populações híbridas de trigo. Bragantia, Campinas, v. 57, n. 1, 1998. Disponível em: <http://www.scielo. $\mathrm{br} / \mathrm{scielo} . \mathrm{php}$ ? script=sci_arttext\&pid=S0006$87051998000100011 \& \operatorname{lng}=\mathrm{en} \& \mathrm{nrm}=$ iso $>$. Acesso em: 19 maio 2014.

CARVALHO, S. P. Métodos alternativos de estimação de coeficientes de trilha e índices de seleção, sob multicolinearidade. Viçosa: UFV, 1995. 163 p.

CARVALHO, F. I. F.; LORENCETTI, C.; BENIN, G. Estimativas e implicações da correlação no melhoramento vegetal. Pelotas: UFPel, 2004. 142 p.

CRUZ, C. D. Programa genes: análise multivariada e simulação. Viçosa, MG: Editora UFV, 2006. 175 p.

CRUZ, C. D.; REGAZZI, A. J. Modelos biométricos aplicados ao melhoramento genético. Viçosa: UFV, $1994.390 \mathrm{p}$.

CRUZ, C. D.; CARNEIRO, P. C. S. Modelos biométricos aplicados ao melhoramento genético. 2. ed. Viçosa: UFV, 2006. v. 2.

EMPRESA BRASILEIRA DE PESQUISA AGROPECUÁRIA - EMBRAPA. Centro Nacional de Pesquisa de Solos (Rio de Janeiro, RJ). Sistema brasileiro de classificação de solos. 2. ed. Rio de Janeiro: EMBRAPA-SPI, 2006. 306 p.

FALCONER, D. S. Introdução à genética quantitativa. Viçosa: UFV, 1987. 279 p.

GOMES, A. S.; SILVA, C. A. S. da; PARFIT, J. M. B.; PAULETTO, E. A.; PINTO, L. F. S. Caracterização de indicadores da qualidade do solo, com ênfase às áreas de várzea do Rio Grande do Sul. Pelotas: EMBRAPA Clima Temperado, 2006. $40 \mathrm{p}$.
GONÇALVES, P. S.; MARTINS, A. L. M.; BORTOLLETO, N. Estimates of genetics parameters and correlations of juvenile characters based on open pollinated of Hevea. Brazilian Journal of Genetics, Ribeirão Preto, v. 19, n. 1, p. 105-111, 1996.

GONDIM, T. C. O.; ROCHA, V. S.; SEDIYAMA, C.; MIRANDA, G. V. Análise de trilha para componentes do rendimento e caracteres agronômicos de trigo sob desfolha. Pesquisa Agropecuária Brasileira, Brasília, v. 43, n. 4, p.487-493, abr. 2008.

HARTWIG, I.; CARVALHO, F. I. F. de; OLIVEIRA, A. C. de; VIEIRA, E. A.; SILVA, J. A. G. da; BERTAN, I.; RIBEIRO, G.; FINATTO, T.; REIS, C. E. S. dos; BUSATO, C. C. Estimativa de coeficientes de correlação e trilha em gerações segregantes de trigo hexaplóide. Bragantia, Campinas, v. 66, n. 2, p. 203-218, 2007.

KUREK, A. J.; CARVALHO, F. I. F.; OLIVEIRA, A. C.; CARGNIN, A.; MARCHIORO, V. S.; LORENCETTI, C. Coeficiente de correlação entre caracteres agronômicos e de qualidade de grãos e sua utilidade na seleção de plantas de aveia. Ciência Rural, Santa Maria, v. 32, n. 3, p. 371-376, 2002.

LOPES, A. C. A.; LOPES, A. C. A.; VELLO, N. A.; PANDINI, F.; ROCHA, M. M.; TSUTSUMI, C. Y. Variabilidade e correlações entre caracteres em cruzamentos de soja. Scientia Agrícola, Piracicaba, v. 59, n. 2, p. 341-348, 2002.

MORENO, J. A. Clima do Rio Grande do Sul. Porto Alegre: Secretaria da Agricultura, 1961. 41 p.

MORO, G. L.; REIS, M. S.; SEDIYAMA, C. S.; SEDIYAMA, T.; OLIVEIRA, A. B. de. Correlação entre alguns caracteres agronômicos em soja (Glycine max L. Merril). Revista Ceres, Viçosa, v. 39, p. 225-232, 1992.

OKUYAMA, L. A.; FEDERIZZI, L. C.; BRABOSA NETO, J. F. Correlation and path analysis of yield and its components and plant traits in wheat. Ciência Rural, Santa Maria, v. 34, n. 6, p. 1701-1708, 2004.

PETR, F. C.; FREY, K. J. Genotypic correlations, dominance and heritability of quantitative characters in oats. Crop Science, Madison, v. 6, n. 3, p. 259-262, 1966.

REUNIÃO DA COMISSÃO BRASILEIRA DE PESQUISA DE TRIGO E TRITICALE - RCBPTT. Informações técnicas para trigo e triticale - safra 2011. Cascavel: COODETEC, 2010. 170 p.

SANTOS, J.; VENCOVSKY, R. Correlação fenotípica e genética entre alguns caracteres agronômicos do feijoeiro (Phaseolus vulgaris, L.). Ciência e Prática, São Paulo, v. 10, n. 3, p. 265-272, 1986. 
SILVA, S. A.; CARVALHO, F. I. F.; NEDEL, J. L. Análise de trilha para componentes de rendimento de grãos em trigo. Bragantia, Campinas, v. 64, n. 2, p. 191-196, 2005.

STEEL, R. G. D.; TORRIE, J. L. Principles and procedures of statistics. New York: McGraw Hill, 1960. $481 \mathrm{p}$.

TAWARE, S. P.; HALVANKAR, G. B.; RAUT, V. M. Variability, correlation and path analysis in soybean hybrids. Soybean Genetics Newsletter, v. 24, n. 1, p. 9698, 1997.

VASCONCELLOS, N. J. S.; CARVALHO, F. I. F.; COIMBRA, J.; SILVA, S. A.; MARCHIORO, V. S.; AZEVEDO, R.; LORECETTI, C. Efeito do ambiente e correlação entre componentes do grão em genótipos de aveia cultivados no Sul do Brasil. Revista Brasileira de Agrociência, Pelotas, v. 4, n. 1, p. 85-88, 1998.
VENCOVSKY, R.; BARRIGA, P. Genética biométrica no fitomelhoramento. Ribeirão Preto: Sociedade Brasileira de Genética, 1992. 496 p.

VESOHOSKI, F.; MARCHIORO, V. S.; FRANCO, F. A.; CANTELlE, A. Componentes do rendimento de grãos em trigo e seus efeitos diretos e indiretos na produtividade. Revista Ceres, Viçosa, v. 58, n. 3, p. 337341, jun. 2011.

WALTON, P. D. The use of a factor analysis in determining characters for yield selection in wheat. Euphytica, Dordrecht, v. 20, n. 3, p. 416-421, 1971.

WRIGHT, S. Correlation and causation. Journal Agriculture Research, Islamabad, v. 20, n. 7, p. 577-585, 1921. 
